\title{
Strategies to enhance efficacy of SPION-labeled stem cell homing by magnetic attraction: a systemic review with meta-analysis
}

This article was published in the following Dove Press journal: International Journal of Nanomedicine

\author{
Ye Ji Ahn ${ }^{1,2}$ \\ Tae Hoon Kong ${ }^{1,2}$ \\ Jin Sil Choi ${ }^{1,2}$ \\ Wan Su Yun ${ }^{3}$ \\ Jaehong Key ${ }^{3}$ \\ Young Joon Seo (iD) ${ }^{1,2}$ \\ 'Research Institute of Hearing \\ Enhancement, Yonsei University Wonju \\ College of Medicine, Wonju, South \\ Korea; ${ }^{2}$ Department of \\ Otorhinolaryngology, Yonsei University \\ Wonju College of Medicine, Wonju, \\ South Korea; ${ }^{3}$ Department of Biomedical \\ Engineering, Yonsei University, Wonju, \\ South Korea
}

\begin{abstract}
Stem cells possess a promising potential in the clinical field. The application and effective delivery of stem cells to the desired target organ or site of injury plays an important role. This review describes strategies on understanding the effective delivery of stem cells labeled with superparamagnetic iron oxide nanoparticles (SPION) using an external magnet to enhance stem cell migration in vivo and in vitro. Fourteen total publications among 174 articles were selected. Stem cell type, SPION characteristics, labeling time, and magnetic force in vivo are considered important factors affecting the effective delivery of stem cells to the homing site. Most papers reported that the efficiency was increased when magnet is applied compared to those without. Ten studies analyzed the homing competency of SPION-labeled MSCs in vitro by observing the migration of the cell toward the external magnet. In cell-based experiments, the mechanism of magnetic attraction, the kind of nanoparticles, and various stem cells were studied well. Meta-analysis has shown the mean size of nanoparticles and degree of recovery or regeneration of damaged target organs upon in vivo studies. This strategy may provide a guideline for designing studies involving stem cell homing and further expand stem cell.
\end{abstract}

Keywords: stem cells, homing, SPION, magnetic attraction, stem cell therapy, systematic review

\section{Introduction}

Application of superparamagnetic iron oxide nanoparticles with the cellular therapies is an attractive option for the localization of stem cells to sites of interest to repair tissue damage. ${ }^{1}$ Stem cell-based therapies are actively studied and used in all areas of regenerative medicine. However, delivery of an appropriate number of cells to defective tissue remains difficult. In addition to stem cells' important abilities such as self-renewal and tissue differentiation, cell migration to damaged cells, known as the homing phenomenon, is also crucial. ${ }^{2}$ Among stem cells types, mesenchymal-derived stem cells (MSCs) have a better homing capacity than induced pluripotent stem (iPS) cells, embryonic stem cells, and others. MSCs are defined to adhere to plastic in culture and differentiate into osteocytes, chondrocytes, and adipocytes. ${ }^{3}$ Additionally, they must express CD105, CD90, and CD73 and lack expression of CD45, CD34, CD14 or CD11b, CD79 alpha or CD19, and HLA-DR surface molecules.

Currently, there is substantial variability in the strategies used to improve MSC homing. Several groups have demonstrated the homing and migration of MSCs; however, only a small portion of the systemically administered MSCs remain on
Correspondence: Young Joon Seo Department of Otorhinolaryngology, Yonsei University Wonju College of Medicine, 20 Ilsan-ro, Wonju, Gangwondo 26426, South Korea

Tel +82337410644

Fax +82337328287

Email okas2000@hanmail.net 
the target organ. ${ }^{4}$ Many groups are investigating methods to enhance membrane expression of CXCR4, a critical receptor for bone marrow homing. ${ }^{5-7}$ Wiehe et al ${ }^{7}$ demonstrated that the CXCR4-stromal-derived factor-1 (SDF-1) axis is critical for homing to the injured myocardium. Shi et $\mathrm{al}^{8}$ showed that MSCs cultured with a cocktail of cytokines induced high surface expression of CXCR4, with chemotactic receptors of SDF-1 $\alpha$ upregulated in ischemic tissue. Because MSCs are trapped in the lung after intravenous injection, Yukawa et $\mathrm{al}^{9}$ modified the administration of transplanted MSCs in combination with heparin treatment and found that this strategy also significantly decreased MSCs trapped in the lungs. Recently, a "magnetic attraction" method for stem cells was developed. ${ }^{10}$ The concept of magnetic tagging and targeting could play an important role for future advances in delivery and noninvasive monitoring of cell-based therapeutic interventions.

Superparamagnetic iron oxide nanoparticle (SPION) was used for monitoring the migration of injected stem cells by magnetic resonance imaging (MRI). ${ }^{11}$ These SPIONs are also well known to be harmless and non-cytotoxic, showing normal MSC viability, proliferation, and differentiation in vivo and in vitro. ${ }^{12,13}$ SPION can move magnetized MSCs where needed under the presence of a static magnetic field. According to Yun et al's ${ }^{14}$ study, SPION-labeled MSCs migrated to injured olfactory tissue guided by a permanent magnet, resulting in improved MSC homing and migration effects in vivo and in vitro, respectively. Song et $\mathrm{al}^{15}$ reported that when an external magnet $(0.32 \mathrm{~T})$ is attached to the skull in the ischemic brain injury rat model for one week, stem cells labeled with SPION after intravenous injection increased 3-fold in the infarct region under the magnet and the infarct size decreased significantly. These theories have long been introduced and can be used to create experimental methods that greatly impact stem cell studies, ${ }^{16}$ but there has been no significant progress over 20 years due to the lack of a standardized protocol for magnetized stem cell homing using SPION for magnetic attraction. The methodology to be established for homing is divided into three categories: first, how SPION labels stem cells and whether it is cytotoxic or affects cell differentiation. Second, how do magnetized stem cells home in on a desired location in vivo, given the specific magnetic forces. It is necessary to consider the route of injection in administration of cell (intravenously or directly), the time taken for cells to move to the desired organs post-injection, and the ideal location of the magnet in vivo, in order to evaluate the therapeutic efficacy of magnetized MSC homing in clinical settings. Finally, in order to better understand homing biology and increase homing efficiency in vivo, it is important to establish standardized protocols for the experiments in vitro such as how to change the cellular homing molecules (Figure 1).

Therefore, studies of stem cells combined with nanobiotechnology can offer many benefits to stem cell research, including cell homing, which is currently the limiting factor for further advances in this field. The aim of this review was to analyze publications on SPION-labeled stem cells and their magnetic attraction in vivo and in vitro and summarize the strategies for improving magnetized MSC homing. By providing information on established experimental methods for many researchers in these fields, we aim to help define the optimal expansion protocols.

\section{Materials and methods}

\section{Search strategy}

This review included original English reports that used SPION-labeled stem cells and a magnetic field to promote
Labeling of stem cell with SPIO

Homing by magnetic attraction in vivo

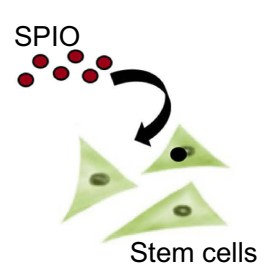

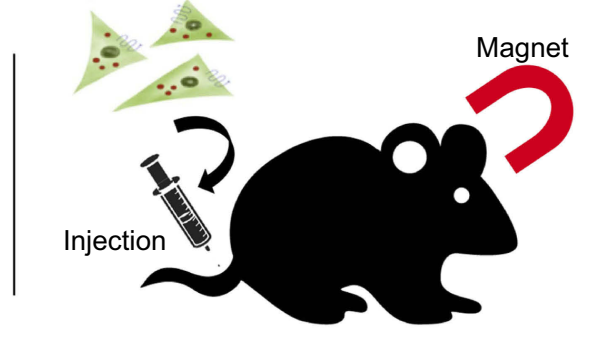

Migration by magnetic attraction in vitro

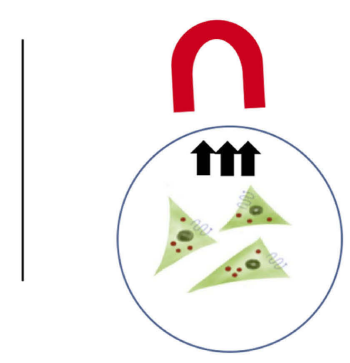

Figure I Schematic representation of enhancement of SPION-labeled stem cell homing with magnetic attraction. 
homing. Studies published between January 2000 and July 2018 were searched in the following databases: EMBASE, PubMed, and Web of Science. The following selected criteria of interests, Boolean operators (DecS/ $\mathrm{MeSH})$, and keyword sequence were used:

(i) EMBASE: "stem cell"/exp OR "stem cell" AND ("iron oxide"/exp OR "iron oxide" OR nanoparticle) AND ("homing") AND "magnetics;"

(ii) PubMed: (((stem cell $[\mathrm{MeSH}$ terms]) AND (iron oxide OR SPION OR nanoparticle)) AND "homing") OR (((stem cell [MeSH terms]) AND (iron oxide OR SPION OR nanoparticle)) AND magnetics);

(iii) Web of Science: TS = (stem cell) AND TS = (nanoparticle) $\mathrm{AND}$ TS $=$ (homing) $\mathrm{OR}$ TS $=($ stem cell $)$ AND TS $=$ (nanoparticle) AND TS $=$ (magnetics) $\mathrm{OR}$ TS $=($ stem cell) $\mathrm{AND}$ TS $=$ (iron oxide) AND $\mathrm{TS}=($ targeting$)$.

Studies which were indexed in more than one database (duplicates); incomplete articles; studies from conferences, book chapters, and non-English papers; and those not related to "nanoparticle" or "stem cells" and "magnetic field" were excluded from this review (Figure 2).

\section{Data compilation and review (data extraction and quality assessment)}

In this review, 2 review authors (Y.J.A. and Y.J.S) have independently extracted and randomly selected data using the search strategies cited earlier and verified the eligibility of the references. Discrepancies in study selection and data extraction that appeared between the two reviewers were discussed with a third reviewer and resolved. The reviewed papers were divided into three categories. The characteristics of the nanoparticles used in the experiment, the results of the in vivo experiments, and the results of the experiments in vitro were analyzed separately in Tables 1-3 respectively. We undertook a quantitative evaluation of data by using random-effect meta-analyses.

\section{Outcome measures}

We focused on data presented in each study as follows: 1) the hydrodynamic size of nanoparticles, 2) results of in vivo experiments such as the number of observed cells in the target organ of each study, and 3) results in vitro. However, the result of in vitro study cannot be analyzed because of the lack of results.

\section{Statistical analysis}

The mean hydrodynamic size of SPIONs was analyzed. The cell number observed experimentally in vivo was compared in "cells/field" units. The raw mean data and standardized mean difference (SMD) were used to pool studies. Between-study heterogeneity was evaluated using the $p$-value and $\mathrm{I}^{2}$ statistics. If $\mathrm{I}^{2}$ was $<50 \%$, the fixedheterogeneity effect model was used, otherwise the random-effect model was performed. All statistical analysis was performed using $\mathrm{R}$ software (v. 3.5.0) for Windows with the meta-package.The $p$-values $<0.05$ were considered statistically significant.

\section{Results}

\section{Overview of the reviewed literature}

A total of 174 articles were identified by applying these search strategies. After applying inclusion criteria and removing duplicated articles, 14 total publications were selected (Figure 2). Although stem cell homing studies were used, a majority of the nanoparticle papers used for tracking MRIs were excluded. In this review article, we wanted to analyze only the use of magnetic force to attract stem cells labeled with nanoparticles. Although 19 years of research were analyzed, active research (6 papers, 43\%) has been conducted over the past seven years. Asia, especially China, Japan, and South Korea, had the greatest number $(43 \%)$ of studies conducted, recently followed by European countries and the United States. The reviewed papers were analyzed according to the characteristics of stem cells and SPIONs used experimentally and according to the experimental designs either in vivo or in vitro.

\section{SPION and stem cell characteristics used in homing experiments}

There were 9 mesenchymal, 1 bone marrow stromal, 1 endothelial progenitor, 1 neural, and 1 cardiosphere-derived cell lineages used (Table 1). Nine studies sourced their stem cells from humans, 5 from rats, 1 from rabbits, and 1 from mice. Concerning nanoparticle structural characteristics, the absolute amount of Fe used in each experiment is important for determining the magnetic force; however, this could be described through the concentration of the SPION labeled. The cell surface charge (zeta potential), nanoparticle size, and coating agent are important factors for enhancing cell labeling. Although the rate at which cells were labeled by nanoparticles by different factors may vary, most studies have reported over $80 \%$ labeling rates in cells were noted. The iron oxide 


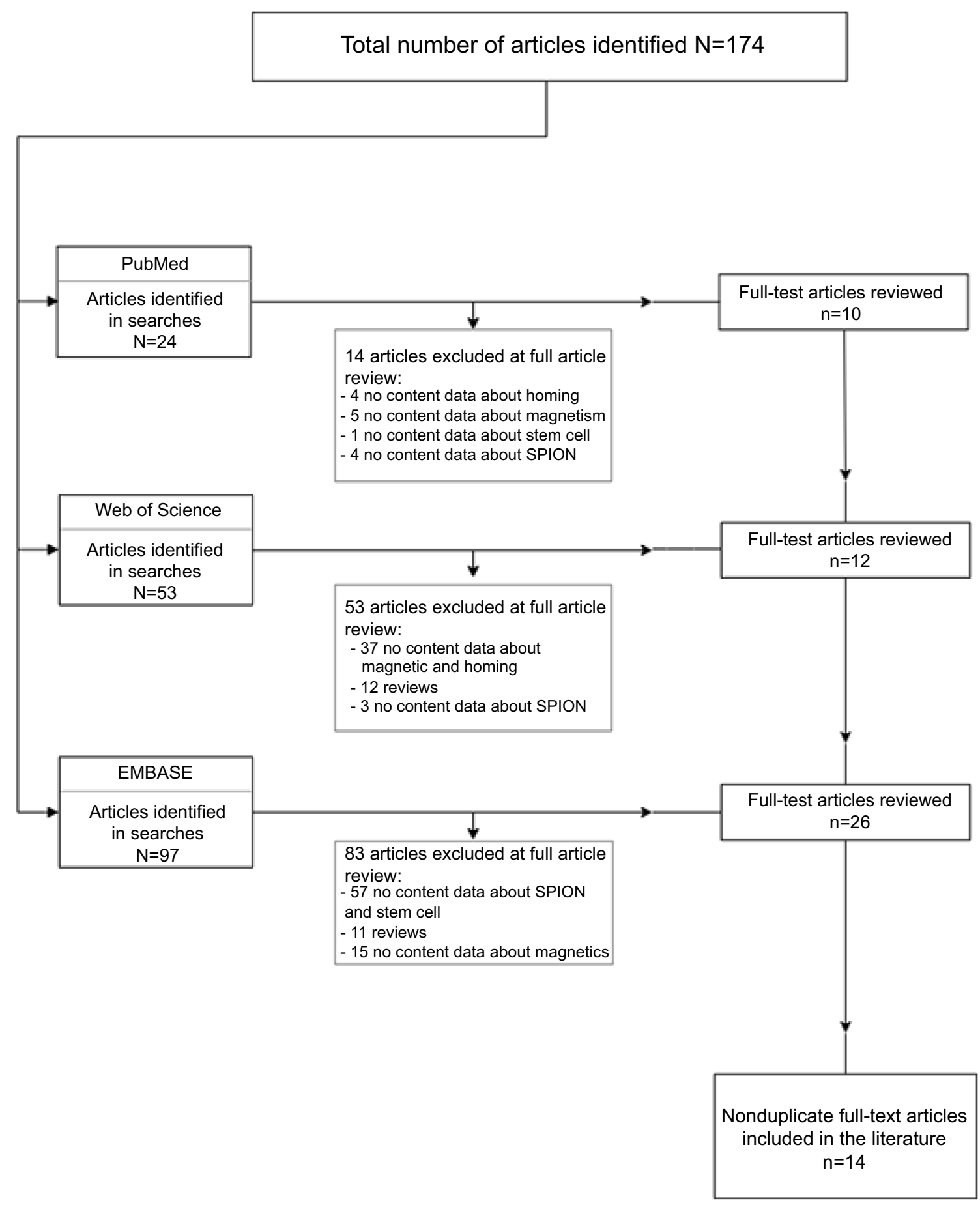

Figure 2 Flowchart of the article screening process for inclusion in this review.

nanoparticles used in eight studies among fourteen selected publications were commercial nanoparticles; the remaining six were laboratory-synthesized. Among studies that had used commercially synthesized iron oxide nanoparticles, four studies used Feridex ${ }^{\circledR}$ or Endorem ${ }^{\mathrm{TM}}$ (Advanced Magnetic, Cambridge, MA, USA), one used Resovist ${ }^{\circledR}$ (Bayer Schering Pharma AG, Berlin, Germany), two used FluidMag
(Chemicell, Berlin, Germany), and one used Molday ION Rhodamine B (BioPAL, Inc., Waltham, MA, USA). These findings suggest that the higher prevalence in utilization of commercially synthesized iron oxide nanoparticles may be due to immediate availability and proven safeness of the material. The diameter of the nanoparticle used ranged from $4 \mathrm{~nm}$ to $1200 \mathrm{~nm}$. In meta-analysis of hydrodynamic size of 


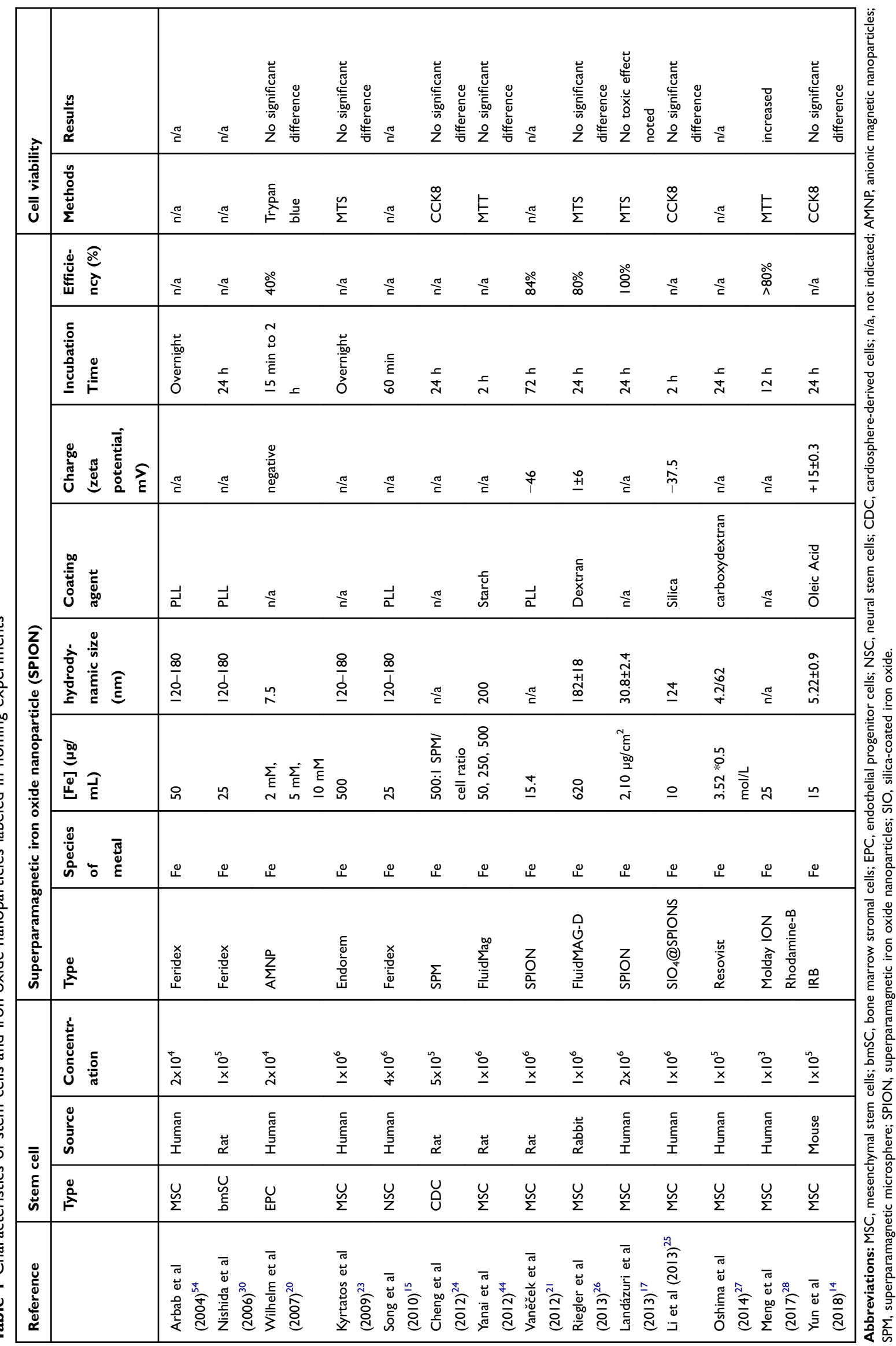




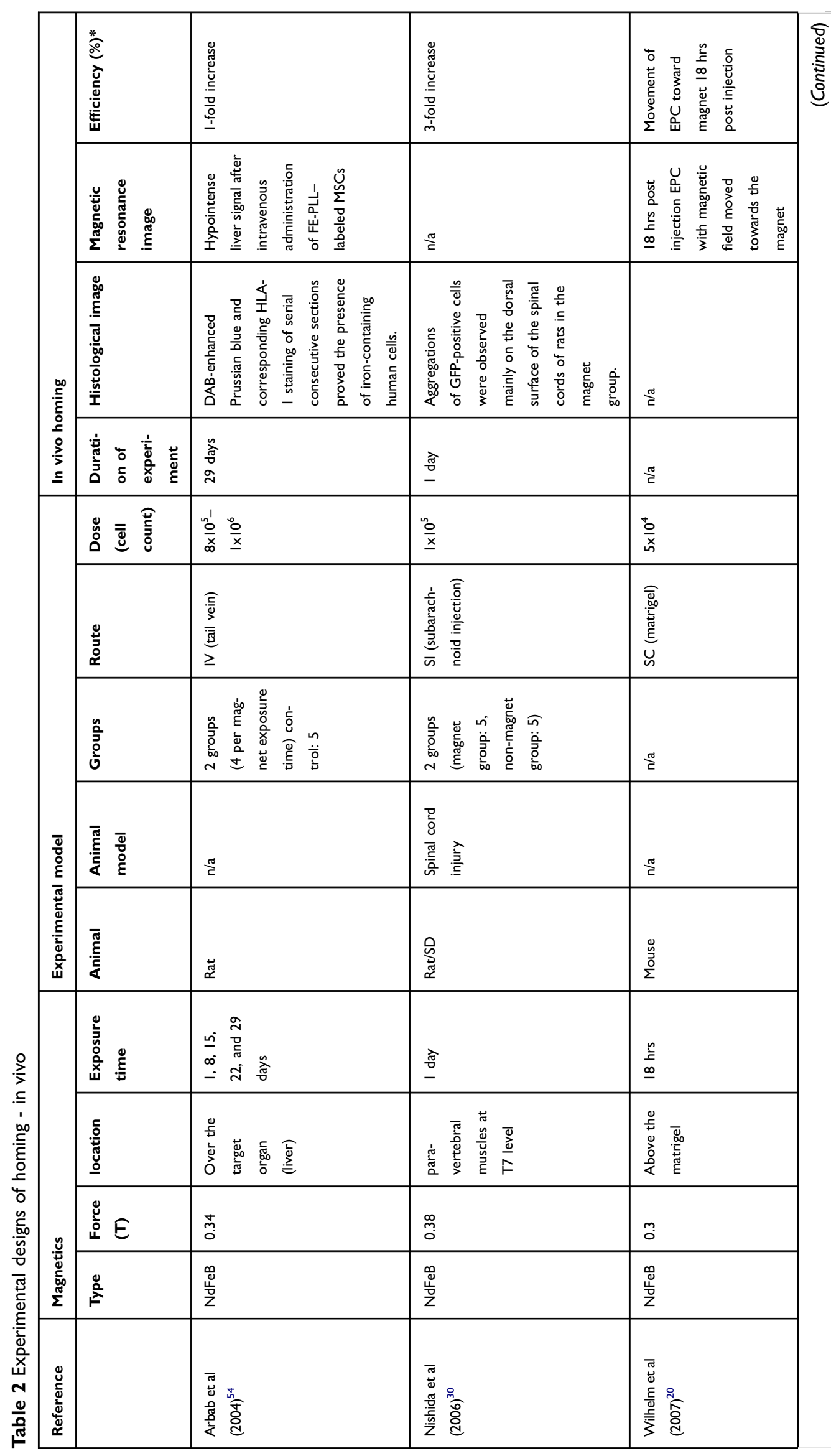




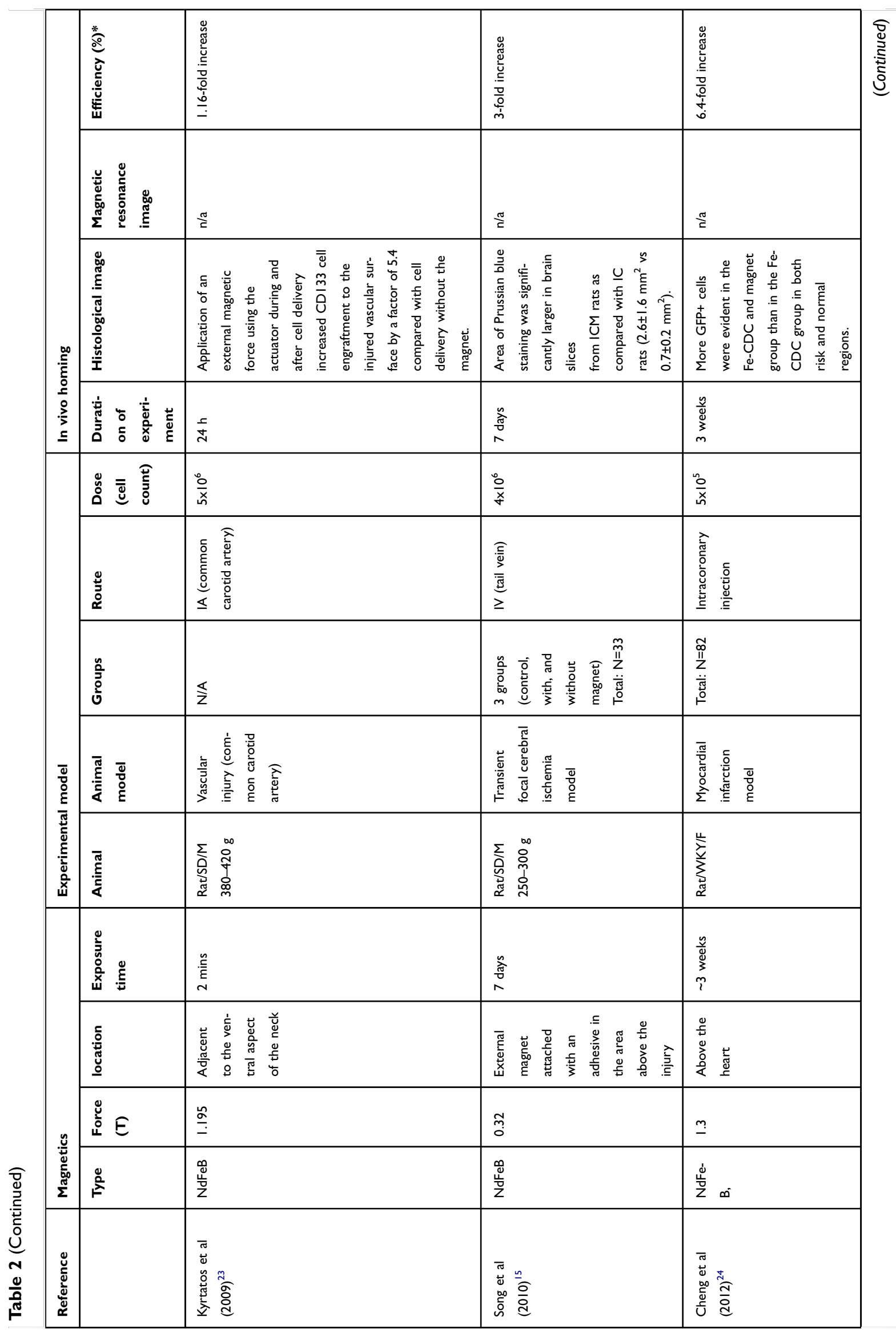




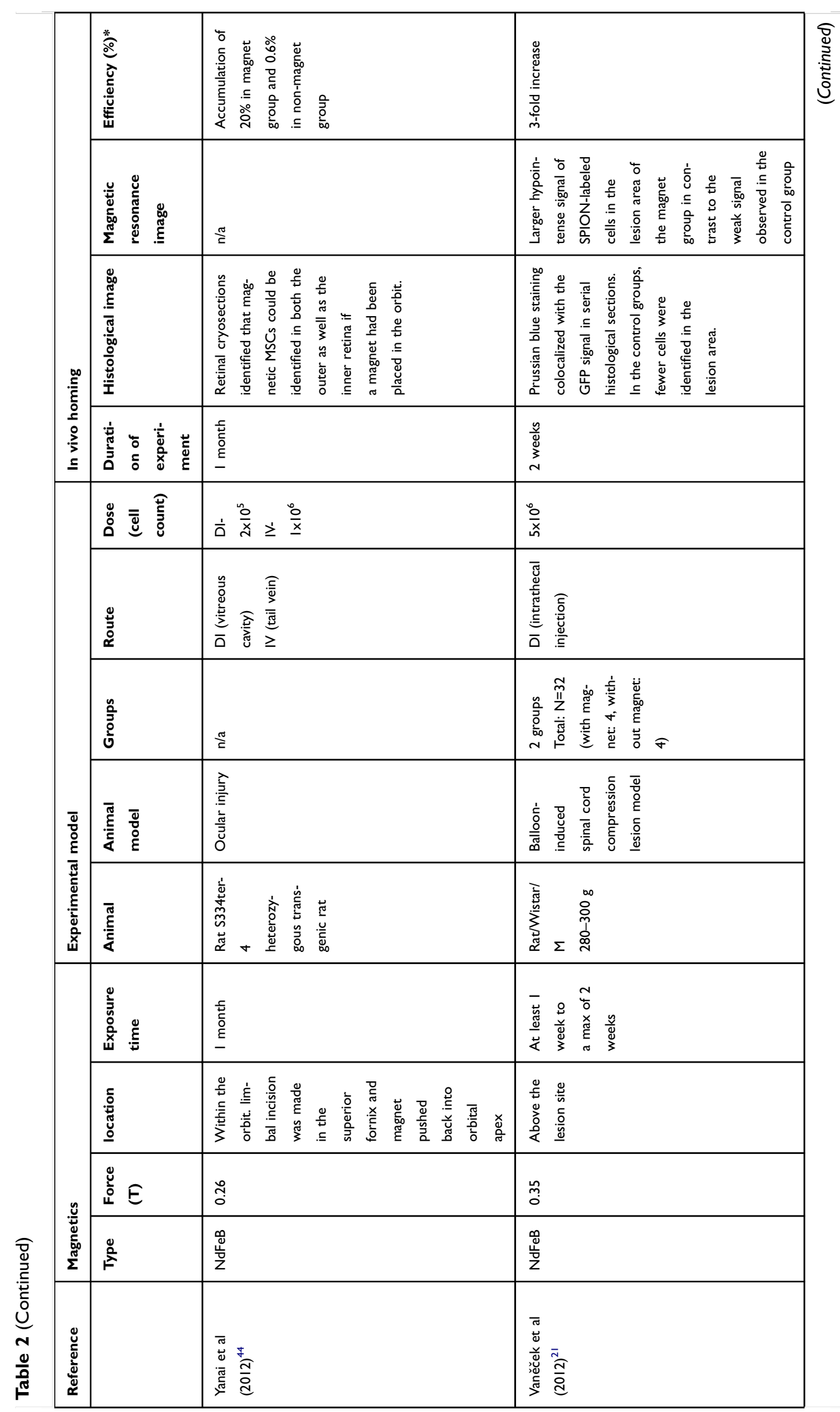




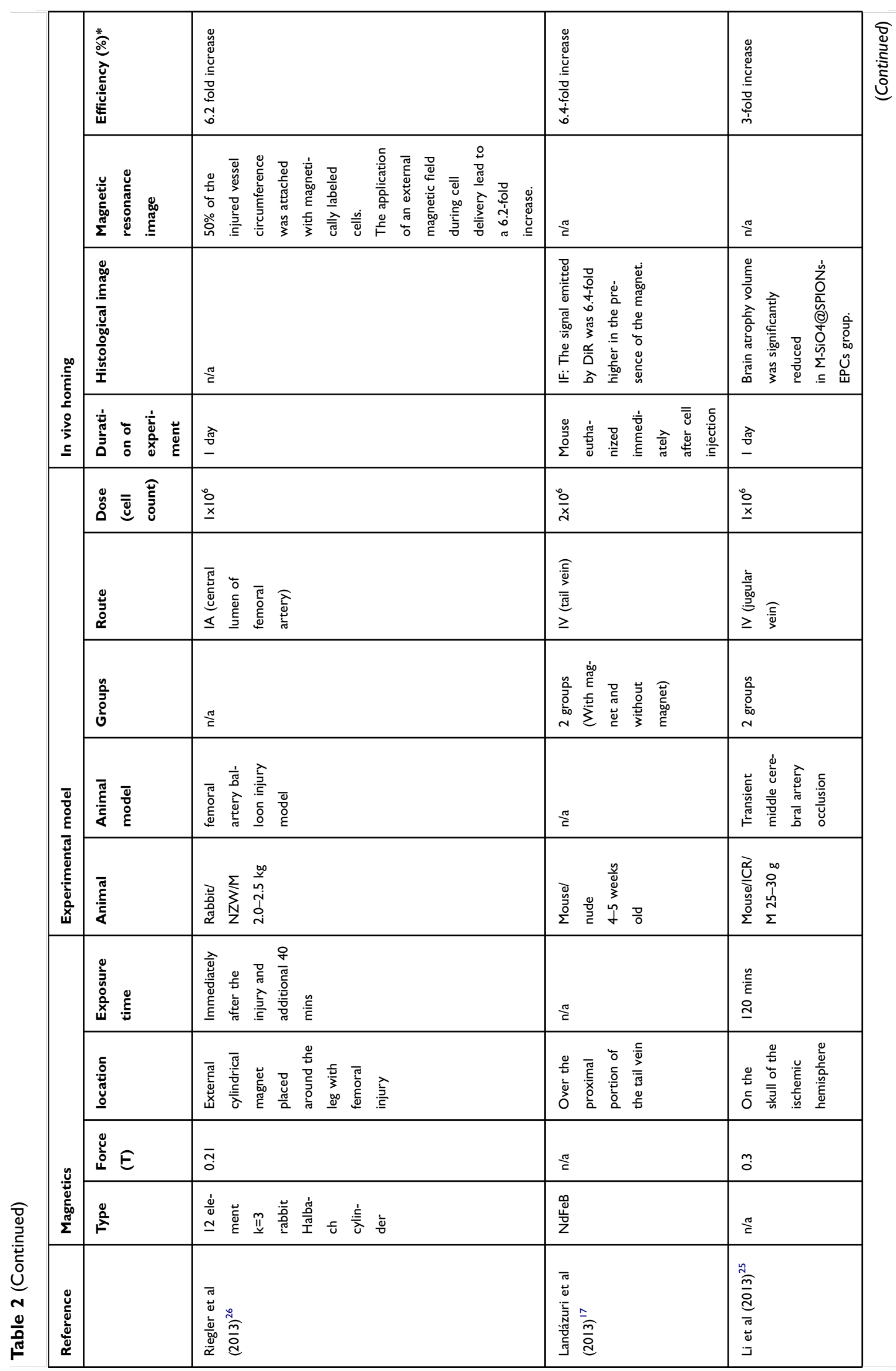




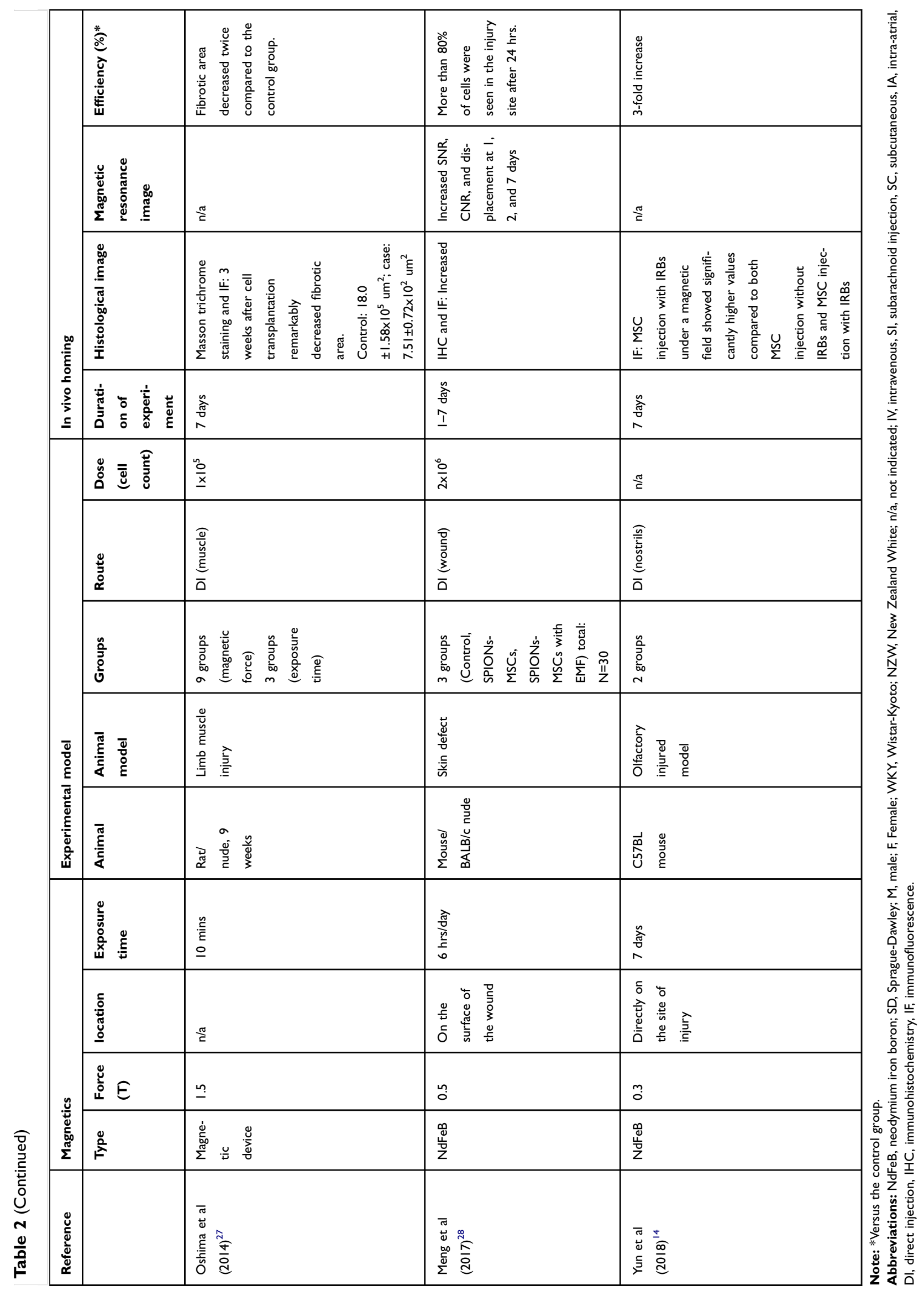




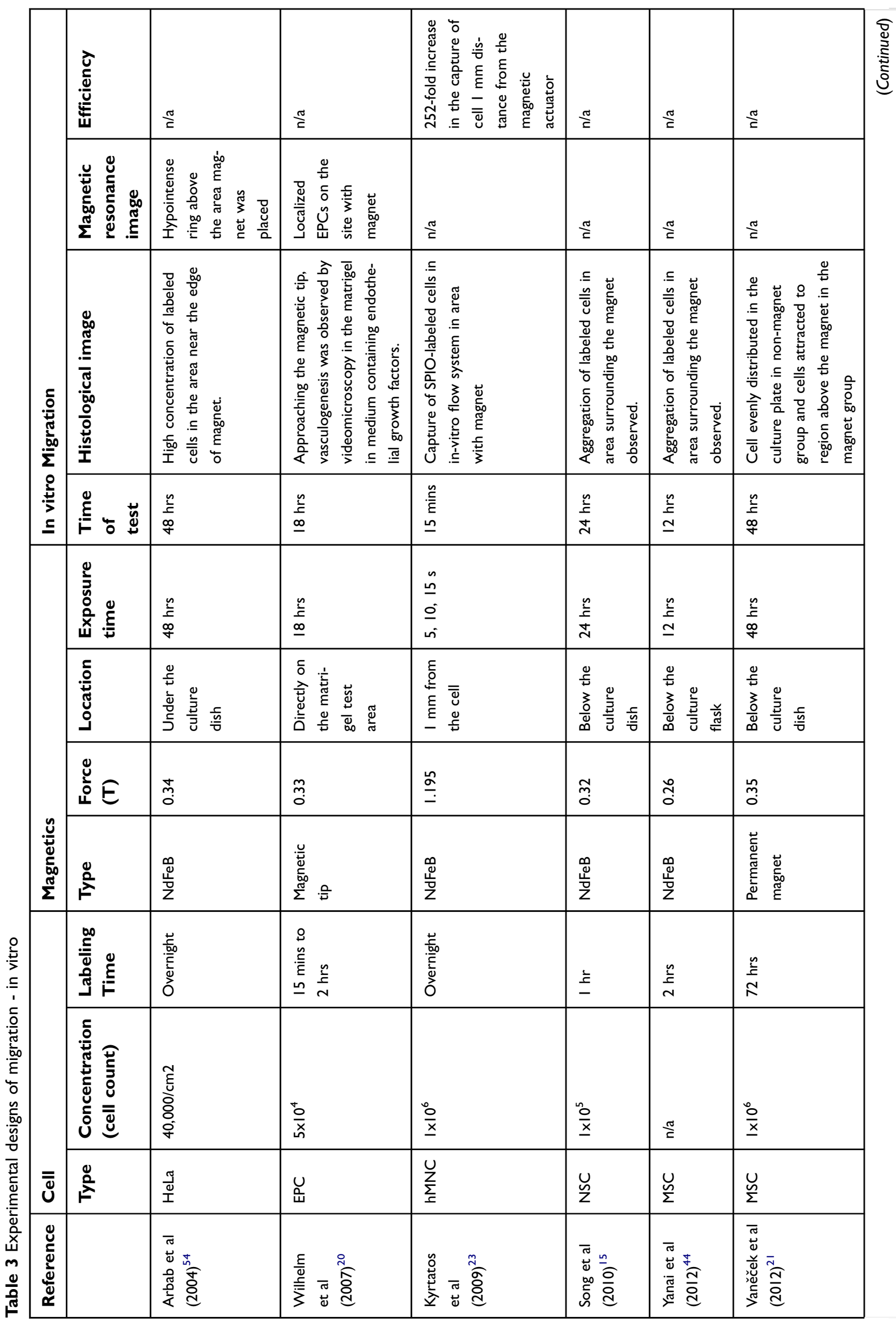




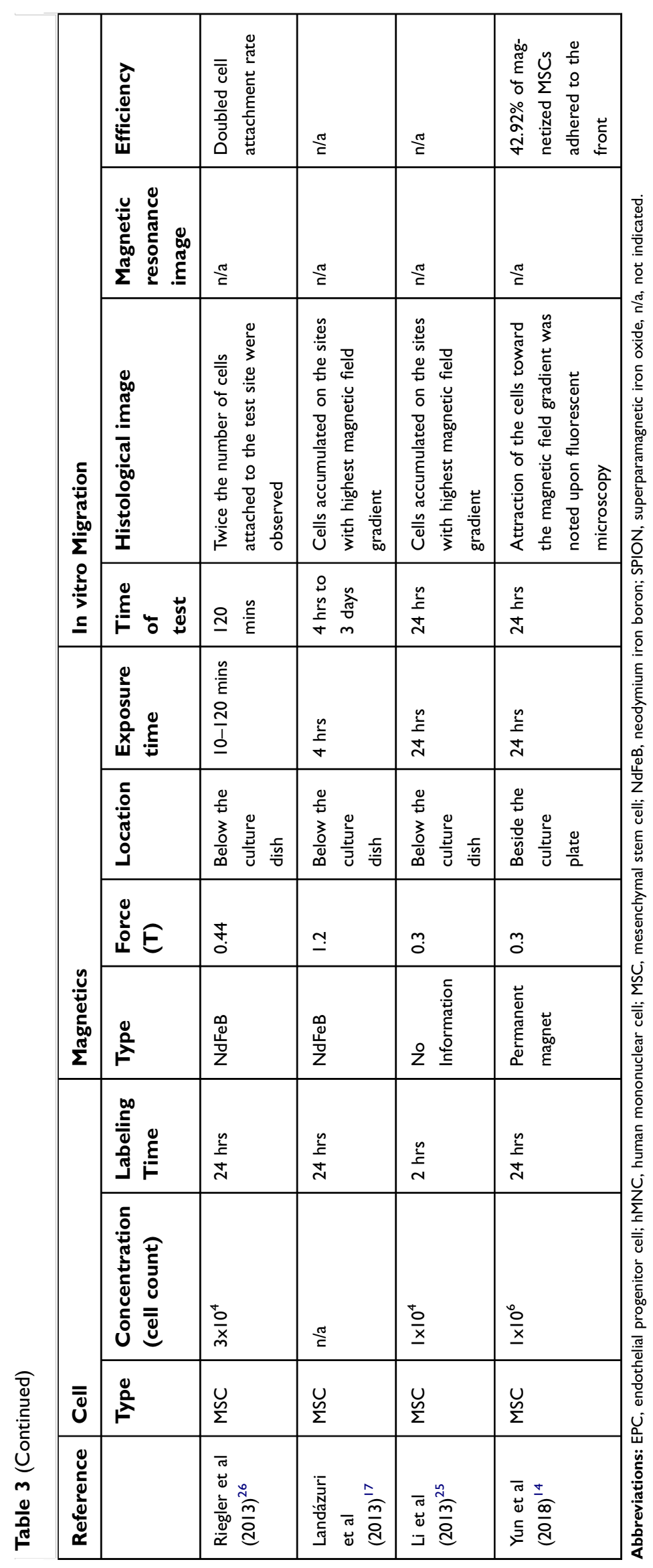


nanoparticles, studies which presented the hydrodynamic size mean and standard deviation and the nanoparticle size were included. Finally, 3 studies were pooled, and the pooled hydrodynamic size was $72.67 \mathrm{~nm}$ (95\% CI: 25.90-119.44) with high heterogeneity $\left(\mathrm{I}^{2}=100 \%\right)$ (Figure 3 ). Riegler et $\mathrm{al}^{11}$ used especially large commercial nanoparticles while Yun et $\mathrm{al}^{14}$ and Landázuri et $\mathrm{al}^{17}$ used relatively small laboratory-synthesized nanoparticles. Thus, high heterogeneity was shown. For commercialized nanoparticles used for homing, sizes up to 120-200 nm were used to label cells, which is the size of clathrin-mediated endocytosis. Smaller nanoparticles were also used in some laboratories, but there was no significant difference in labeling efficiency. SPION coating with polyL-lysine (PLL) as the transfection agent was demonstrated in most of the reviewed studies. In addition to PLL, starch, dextran, silica, and oleic acid were used; these are commonly known as harmless to the human body. To insert nanoparticles into cells for labeling, the zeta potential in contact with the negatively charged cell surface is important. While most selected studies did not report the material's charge, many were negative. Negatively charged nanoparticles have a lower capacity for cell entry than positively charged ones because the cell surface is also negatively charged. ${ }^{18,19}$ However, when internalized by the cell, negatively charged nanoparticles show less cytotoxicity and are thus preferred. The nanoparticle concentration used for labeling ranged from 2 to $500 \mu \mathrm{g} / \mathrm{mL}$. The stem cell concentration used for labeling ranged from $2 \times 10^{4}$ in Wilhelm et al ${ }^{20}$ to $4 \times 10^{6}$ in Song et al. ${ }^{15}$ The labeling time for nanoparticles to enter stem cells ranged from $15 \mathrm{~min}$ in Wilhelm et $\mathrm{al}^{20}$ to $72 \mathrm{hrs}$ in Vaněček et al; ${ }^{21}$ a labeling time of $24 \mathrm{hrs}$ was most commonly used. Stem cells were commonly incubated with nanoparticles for $24 \mathrm{hrs}$, but the shortest time ranged from 15 mins to $2 \mathrm{hrs}$. Therefore, by the mean rate of labeling time applied in the different kinds of literature, $24 \mathrm{hrs}$ are recommended to maintain high-efficiency labeling. When cell viability was observed at these incubation times, none of 11 papers reported cytotoxicity. To determine cell viability, 4 studies used cell counting kit (CCK), 3 used 3-(4,5-dimethylthiazol-2-yl)-5-(3-carboxymethoxyphenyl)-2(4-sulfophenyl)-2H-tetrazolium (MTS), 2 used Dimethylthiazol-2-yl)-2,5-diphenyltetrazolium bromide (MTT), 1 used trypan blue and 1 used CASY2 analyzer.

\section{Migration of SPION-labeled stem cells by magnetic attraction in vitro}

Ten studies analyzed the homing competency of the iron oxide nanoparticle-labeled MSCs by observing the migration of the cell toward the external magnet (Table 3). Wilhelm et $\mathrm{al}^{22}$ used video microscopy to observe migration of the labeled cell. After endothelial precursor cells (EPCs) were magnetically labeled via 2 hr incubation, the cells were seeded in Matrigel applied by a thin magnetic tip of $0.33 \mathrm{~T}$. Cells massively migrate toward this tip (over 2-4 hrs) to form dense tissue surrounding the tip (14 hrs). Kyrtatos et $\mathrm{al}^{23}$ reported the highest migration efficacy in vitro among selected studies, showing a rapid movement toward the magnet of 19 $\mathrm{pN}$ at 5-15 $\mathrm{s}$ in real-time video. They developed an "in vitro flow system" with a 5 bar magnet array in aluminum casing for evaluating intraluminal migration and suggested the possibility for the magnetic control of cells inside the vasculature using a circumferential external magnetic force. They found that capturing cells in vitro for $15 \mathrm{mins}$ at $1 \mathrm{~mm}$ resulted in 252-fold increase in capture rate $\left(\right.$ mean $=41 \times 10^{3} \pm 6 \times 10^{3}$ cells $)$ versus control specimens (mean $=163 \pm 41$ cells). Yun et $\mathrm{al}^{14}$ showed the quantitative result of magnetically dragging MSCs with a $0.3 \mathrm{~T}$ permanent magnet affected the cells at a distance of $15 \mathrm{~mm}$, increasing cell density by $43 \%$ (at $0-5 \mathrm{~mm}$ ). Results analyzed in vitro could not be quantitatively compared or meta-analyzed due to a lack of data.

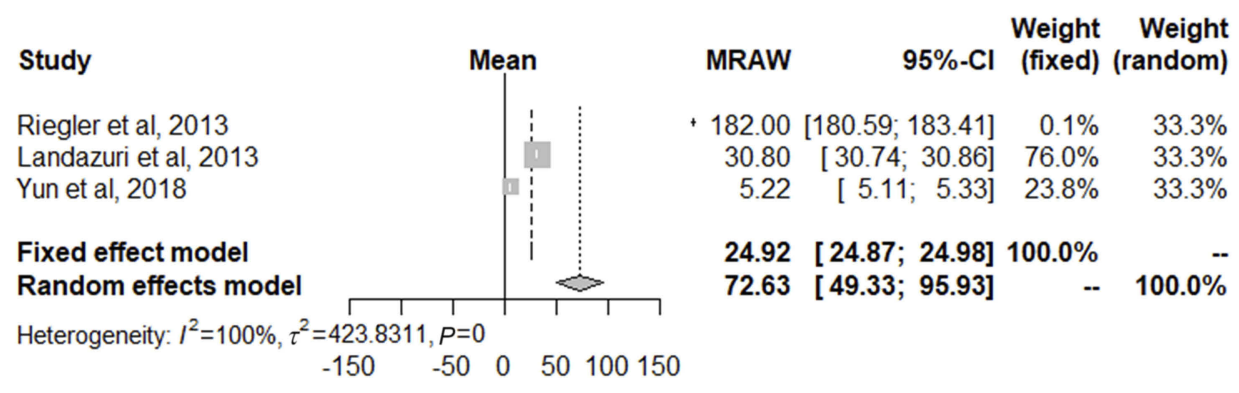

Figure 3 Forest Plot showing hydrodynamic size of nanoparticles and meta-analysis results of mean hydrodynamic size of nanoparticles. 


\section{Homing of SPION-labeled stem cells by magnetic attraction in vivo}

For in vivo experiments, the magnet's force and location of placement were considered as an important factor for attracting magnetized cells. The homing of iron oxide nanoparticle-labeled MSCs was enhanced through the application of a magnet to a desired site (Table 2). Nine studies used a neodymium iron boron magnet, 2 used a permanent magnet, 2 used a magnetic device, 1 used a magnetic tip, and 1 study did not mention the magnet type. The corresponding magnetic forces ranged from $0.21 \mathrm{~T}$ to $1.5 \mathrm{~T}$.

Of these selected publications, 8 studies used rats, 5 used mice, and 1 used rabbits. Among the experimental animal models, 5 used a vascular injury model, 2 used a spinal cord injury model, 1 used muscular injury model, 1 used skin injury model, 1 used cardiac injury model, 1 used ocular injury model, and 1 used olfactory injury models. The most common type was the vascular injury model; three used thread occlusion ${ }^{15,24,25}$ and two performed balloon inflation to cause injury. ${ }^{23,26}$

Iron oxide nanoparticle-labeled MSC dosage ranged from $5 \times 10^{4}$ to $5 \times 10^{6}$. The routes of stem cell administration in the selected studies were 5 studies by direct injection to the injury site, 4 studies by intravenous injection, 2 studies by intra-arterial injection, and 1 study by subcutaneous injection. The in vivo homing experiment was observed from immediately to 1 month. Four studies observed the experiment until day $7,{ }^{14,15,27,28}$ while 2 studies, ${ }^{29,30}$ observed for about 1 month in order to determine the duration of MSC retention in the injury site. The researchers were able to observe MSC in the site of injury until 1-month post-administration.

The reviewed studies observed an enhanced migration capacity of SPION-labeled MSCs to the injury site with or without application of an external magnetic field to promote effective delivery of MSCs to the desired site. Although there have been few papers reported specific values for homing efficiency in vivo, most papers reported that the efficiency was increased when magnet is applied compared to those without. Cheng et $\mathrm{al}^{24}$ reported that the efficiency in a myocardial infarction rat model can be increased about 6.4-fold with a $1.3 \mathrm{~T} \mathrm{NdFeB}$ magnet above the heart. Yun et $\mathrm{al}^{14}$ used a $0.3 \mathrm{~T}$ permanent magnet directly on the site of injury in the olfactory-injured mouse model, showing a high efficiency of a 3-fold increase after 7 days. Six studies have used MRIs to assess the therapeutic efficacy of stem cell homing with the application of an external magnet, and 13 of 14 selected publications had histological images taken either in immunohistochemistry (IHC) or immunofluorescence (IF).

In meta-analysis, quantitative comparisons of observed stem cells at the target organ were performed with and without magnets. Studies were included that reported the mean and standard deviation of observed stem cells in the target organ and the number of subjective animals. Finally, 5 studies were pooled. The SMD of the pooled magnet was 2.23 (95\% CI: $0.43-4.03)$ with moderate heterogeneity ( $p$-value $=0.05, \mathrm{I}^{2}=58 \%$, Figure 4$)$.

\section{Discussion}

Stem cell-based therapies are rapidly evolving for several diseases such as strokes, myocardial infarctions, liver diseases, and demyelinating/dysmyelinating disorders of the central nervous system. ${ }^{31-35}$ Karp and Leng $\mathrm{Teo}^{36}$ suggested defining cellular homing as an arrest of MSCs within the vasculature of the respective tissue followed by a transmigration process across the endothelium. Several stem cells including MSCs and EPCs, which are multipotent regarding regeneration, are currently used due to their ability to migrate toward damaged tissue. They also exhibit an intrinsic homing property enabling them to direct migration to sites of injury, inflammation, and tumors. ${ }^{37-39}$ However, approaches which rely on cell delivery suffer

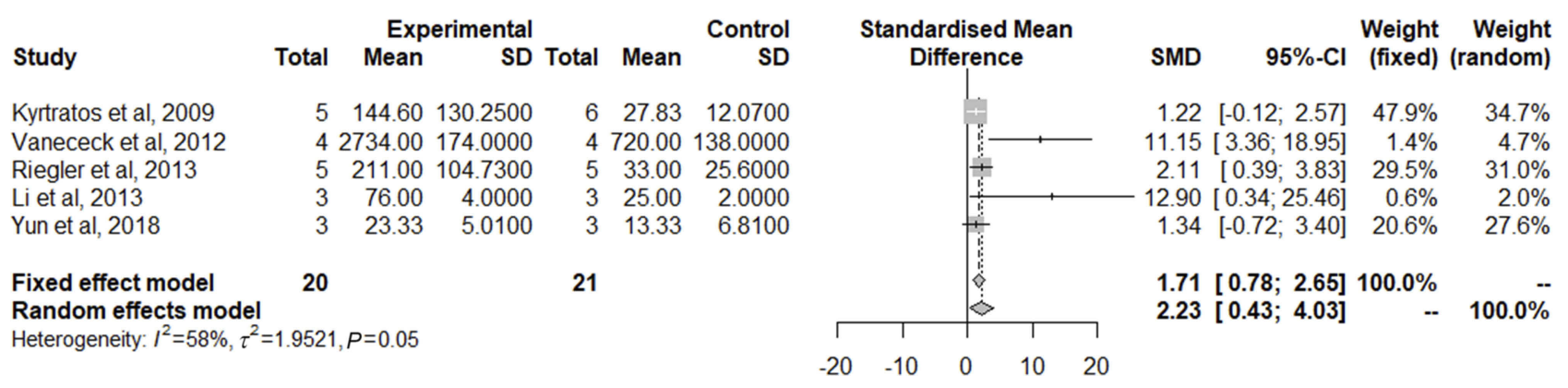

Figure 4 Forest plot showing stem cell observed in the target organ and meta-analysis results for quantitative comparison. 
from poor cell retention at the target site and has potential for adverse effects due to generalized distribution. ${ }^{40}$ Devine et $\mathrm{al}^{4}$ demonstrated a low engraftment efficacy, estimated to range from $0.1 \%$ to $2.7 \%$ and observed in the kidney, lung, liver, thymus, and skin. Lee et $\mathrm{al}^{41}$ recently quantified MSC accumulation in the lungs after systemic administration. They found the presence of nearly all (80\%) infused MSC in the lungs 15 mins after infusion; after 4 days, the humanspecific signal decreased exponentially to $0.01 \%$. Thus, several methodologies have been applied to increase the efficacy of stem cell homing.

The measurement of the velocity of magnetically labeled cells submitted to a magnetic field gradient was referred to as magnetophoresis, ${ }^{42}$ attracting interest as a new approach. ${ }^{22}$ However, the in vivo mechanisms involved in MSC homing and the conditions which govern their homing behavior are still poorly understood and require extensive in vitro and in vivo testing. Several factors are important, including the cellular iron concentration, effective cellular SPION saturation, cellular nanoparticle distribution, external magnetic field strength, magnetic field gradient, injection methodology, and especially the design of animal experiments regarding clinical translation. This review focuses on the current knowledge of magnetically labeled stem cell homing toward an external magnetic field. It is important for the future use of MSCs as a cellular therapeutic agent. Song et $\mathrm{al}^{15}$ demonstrated that rats wearing an external magnet $(0.32 \mathrm{~T})$ on their skull for 1 week exhibited an increased number of SPION-labeled stem cells after intravenous injection, resulting in a 3-fold or greater increase in the infarct area below the magnet as well as a significant decrease in infarct size. Shen et $\mathrm{al}^{10}$ introduced another approach for the magnetic attraction of stem cells to injury sites after traumatic brain injury via intra-carotid delivery. Hsiao et $\mathrm{al}^{43}$ reported that using $1.5 \mathrm{~T}$ MRI at single-level $3 \mathrm{~d}$ gradient echo sequence for 4 repetitions have detected about $45.2 \%$ of the labeled MSCs. Yun et al's study ${ }^{14}$ suggested the possibility that magnetic retention of SPION-labeled MSCs can increase the homing efficiency of MSCs clinically. MSCs labeled with nanoparticles under a magnetic field also showed a significant difference in the olfactory-injured mice model compared to MSCs injected without nanoparticles $(p \leq 0.05)$.

The application of SPION in the nanomedical field has been increasing; with the recent advances in tissue engineering technologies, various experimental trials have been undergone using SPION. ${ }^{11,15,44,55}$ Despite of debates on
SPION toxicity caused by concentration, size, zetapotential, and oxidative stress effect, the SPION is also well known to be widely used in biomedical applications, for example, magnetic resonance imaging, targeted delivery of drugs or genes, and in hyperthermia. Some kind of SPIONs were approved by FDA and commercially available, and other synthesized SPION which have undergone cell viability tests to verify the cytotoxic effect were used. In the studies we have reviewed, many researchers suggest that SPION is safe to use in in vitro and in vivo examinations. Most of these studies used commercially available SPIONs as they are FDA-approved materials; However Resovist $^{\circledR}$ is now available only in few countries and Feridex $^{\circledR}$ has been stopped development and have withdrawn from the market due to economic reasons. ${ }^{45}$ Jo et al $^{46}$ indicated that it is practically necessary for efficient cell labeling to accurately control the size and surface state of the iron oxide nanoparticles. SPION labeling has several limitations. First, as the labeling of these particles is timeconsuming, transfection agents are added to enhance cellular uptake of the particles. Most of the reviewed studies used PLL as this transfection agent, functioning as a coating on SPIONs; PLL is commonly used to enhance cell adhesion to the culture dish in vitro and is a prospective vehicle for transporting nanoparticles into cells. Increasing the particle coating or reducing its breakdown when internalized within a cell can greatly reduce toxicity. ${ }^{47}$ Thus, these findings suggest that coating nanoparticles with a transfection agent enhances the efficacy of cellular SPION-labeling. Second, the SPION surface potential also contributes to cellular internalization. Jo et $\mathrm{al}^{46}$ suggests that since the cell surface is negatively charged, nanoparticles with positive surface potentials would ionically interact with the cell surface and result in the enhanced cell internalization of nanoparticles. Third, SPION size is considered as a strong factor of efficient cellular SPION labeling since different particle sizes are correlated with different endocytosis pathways. Arbab et al, ${ }^{29}$ Nishida et al, ${ }^{30}$ Kyrtatos et al, ${ }^{23}$ Song et al, ${ }^{15}$ Riegler et al, ${ }^{11}$ and $\mathrm{Li}$ et $\mathrm{al}^{25}$ used SPION sizes greater than $120 \mathrm{~nm}$.

A nanoparticle placed in the external milieu of a cell can interact with the exterior of the plasma membrane, which can lead to nanoparticle entry through a process termed endocytosis. The pathway through which the nanoparticles are internalized is yet to be known; however, due to their shape and size, it is assumed that they are internalized through caveolae-mediated or clathrinmediated endocytosis. ${ }^{13,48}$ Huang et al $^{17}$ proposed that 
the internalization of nanoparticles had a stimulatory effect leading to an increase in reactive oxygen species (ROS) due to hypoxic conditions. Excess ROS are generated during a variety of cell stresses and may contribute to inflammation and cell or tissue damage. ${ }^{49}$ Yun et $\mathrm{al}^{14}$ also demonstrated that the increase in CXCR4 by MSC internalization of iron oxide nanoparticles improved magnetized MSC homing to the injury site by SDF-1/CXCR4 chemotaxis. When cells are labeled with SPION, they exhibit issues concerning cytotoxicity or differentiation, and this is of great clinical concern. In the reviewed 14 studies, no cytotoxicity was noted in the SPION-labeled stem cells. This suggests the safety of iron oxide nanoparticles as a labeling agent to enhance homing rates.

Most of the reviewed studies applied the external magnet directly to the site of interest to enhance the homing effect of the MSC. The World Health Organization (WHO) suggests occupational limits for the general public of $5,000 \mathrm{mG}$ (milligauss) and 1,000 $\mathrm{mG}$ for electric and magnetic fields, respectively. Schäfer et $\mathrm{al}^{50}$ proposed that the paramagnetic ions $\mathrm{NA}^{+}$and $\mathrm{K}^{+}$are crucial for maintaining membrane potential, and their distribution may be influenced by magnetic fields; thus, further investigation is needed to determine the molecular mechanisms of interactions between stem cell biology and magnetic fields. According to Marycz et al, ${ }^{51}$ the static magnetic field is classified as a weak $(<1 \mathrm{mT})$, moderate $(1 \mathrm{mT}$ to 1 $\mathrm{T}$ ), strong (1 $\mathrm{T}$ to $5 \mathrm{~T}$ ), or ultrastrong $(>5 \mathrm{~T}$ ) field. Most reviewed papers used magnets with a moderate magnetic field, and no changes in cell viability were shown. Lew et $\mathrm{al}^{52}$ suggested that the proliferation of dental pulp stem cells enhanced by a $0.4 \mathrm{~T}$ static magnetic field (SMF) is considered to be a model of the p38 MAPK signaling pathway as well as intracellular calcium ion activation. Most reviewed papers applied a magnet to the external surface of the injury site; this may be due to easy application and to avoid the risk of infection during surgical insertion of the magnet. The magnet application site and type may vary according to the target organ or area. ${ }^{53}$

In meta-analysis of our study, there are different types of nanoparticles, stem cells, animal models, and target organs used in each study, resulting in a bias in statistical results. Our meta-analysis shows just basic information of previous studies. However, in most of the studies we reviewed, the detailed quantitative results were not disclosed even in supplements, which become a major limitation of our study. The future studies will be suggested that it is desirable to be able to present quantitative results together. Regarding SPIONs, many reports did not show the number, size, or zeta potential of the SPIONs used. Some studies did not report the number of stem cells observed in each target organ, but they showed the degree of recovery or regeneration of damaged target organs in vivo. In in vitro studies, quantifiable results were rarely reported. Additional studies should be reported in the future and accompanied by quantitative reports.

\section{Conclusion}

This review has provided information on overall experimental methods. However, further studies should be conducted. First, the mechanism of endocytosis during SPION labeling should be clarified. We must reveal the mechanisms used, from endocytosis to exocytosis, and develop various types of SPIO for reliable labeling. If we can control this mechanism, safer magnetized MSCs can be produced clinically. Using magnetic attraction, location tracking via MRI would be able to accurately evaluate the efficiency of magnetized MSCs. It will be necessary to develop a SPION that is safe, noncytotoxic to stem cells, and able to maximize magnetic attraction. This is also important to ensure the localization of the circulating cells to the desired location in the vascular system without being washed out in the lungs. Although there are many important issues to address, cell therapies using the attraction of magnetized MSCs are suggested as potential treatment, repair, or replacement strategies for stem cells.

\section{Acknowledgments}

This work was supported by the Gangwon Institute for Regional Program Evaluation grant funded by the Korean Government (Ministry of Trade, Industry and Energy) (No. R0005797), by the Commercialization Promotion Agency for R\&D Outcomes (COMPA) funded by the Ministry of Science and ICT (Development of algorithm for self-diagnosis and self-rehabilitation in peripheral dizziness and a device of portable VNG), and the Technology Innovation Program (20001819) funded by the Ministry of Trade, Industry \& Energy (MOTIE, Korea).

\section{Disclosure}

The authors report no conflicts of interest in this work.

\section{References}

1. Bjornson CR. Turning brain into blood: a hematopoietic fate adopted by adult neural stem cells in vivo. Science. 1999;283(5401):534-537. doi:10.1126/science.283.5401.534 
2. Kang SK, Shin IS, Ko MS, Jo JY, Ra JC. Journey of mesenchymal stem cells for homing: strategies to enhance efficacy and safety of stem cell therapy. Stem Cells Int. 2012;2012(5):1-11. doi:10.1155/ 2012/342968

3. Dominici M, Le Blanc K, Mueller I, et al. Minimal criteria for defining multipotent mesenchymal stromal cells. The International Society for Cellular Therapy position statement. Cytotherapy. 2006;8 (4):315-317.

4. Devine SM, Cobbs C, Jennings M, et al. Mesenchymal stem cells distribute to a wide range of tissues following systemic infusion into nonhuman primates. Blood. 2003;101(8):2999-3001.

5. Keating A. How do mesenchymal stromal cells suppress T cells? Cell Stem Cell. 2008;2(2):106-108.

6. Rombouts WJC, Ploemacher RE. Primary murine MSC show highly efficient homing to the bone marrow but lose homing ability following culture. Leukemia. 2003;17(1):160-170.

7. Wiehe JM, Kaya Z, Homann JM, et al. GMP-adapted overexpression of CXCR4 in human mesenchymal stem cells for cardiac repair Int J Cardiol. 2013;167(5):2073-2081.

8. Shi M, Li J, Liao L, et al. Regulation of CXCR4 expression in human mesenchymal stem cells by cytokine treatment: role in homing efficiency in NOD/SCID mice. Haematologica. 2007;92(7):897-904.

9. Yukawa H, Watanabe $\mathrm{M}$, Kaji N, et al. Monitoring transplanted adipose tissue-derived stem cells combined with heparin in the liver by fluorescence imaging using quantum dots. Biomaterials. 2012;33 (7):2177-2186

10. Shen WB, Plachez C, Tsymbalyuk O, et al. Cell-based therapy in TBI: magnetic retention of neural stem cells in vivo. Cell Transplant. 2016;25(6):1085-1099.

11. Riegler J, Wells JA, Kyrtatos PG, et al. Targeted magnetic delivery and tracking of cells using a magnetic resonance imaging system. Biomaterials. 2010;31(20):5366-5371. doi:10.1016/j. biomaterials.2010.03.032

12. Conner SD, Schmid SL. Regulated portals of entry into the cell. Nature. 2003;422(6927):37-44. doi:10.1038/nature01451

13. Alvarim LT, Nucci LP, Mamani JB, et al. Therapeutics with SPION-labeled stem cells for the main diseases related to brain aging: a systematic review. Int J Nanomedicine. 2014;9:3749-3770. doi:10.2147/IJN.S65616

14. Yun W, Choi J, Ju H, et al. Enhanced homing technique of mesenchymal stem cells using iron oxide nanoparticles by magnetic attraction in olfactory-injured mouse models. Int J Mol Sci. 2018;19(5):1376. doi:10.3390/ijms19051376

15. Song M, Kim YJ, Kim YH, et al. Using a neodymium magnet to target delivery of ferumoxide-labeled human neural stem cells in a rat model of focal cerebral ischemia. Hum Gene Ther. 2010;21 (5):603-610. doi:10.1089/hum.2009.144

16. Becker AD, Riet IV. Homing and migration of mesenchymal stromal cells: how to improve the efficacy of cell therapy? World J Stem Cells. 2016;8(3):73. doi:10.4252/wjsc.v8.i3.73

17. Landázuri N, Tong S, Suo J, et al. Magnetic targeting of human mesenchymal stem cells with internalized superparamagnetic iron oxide nanoparticles. Small. 2013;9(23):4017-4026. doi:10.1002/ smll.201300570

18. Salatin S, Yari Khosroushahi A. Overviews on the cellular uptake mechanism of polysaccharide colloidal nanoparticles. J Cell Mol Med. 2017;21(9):1668-1686.

19. Fröhlich $\mathrm{E}$. The role of surface charge in cellular uptake and cytotoxicity of medical nanoparticles. Int J Nanomedicine. 2012;7:5577-5591.

20. Wilhelm C, Bal L, Smirnov P, et al. Magnetic control of vascular network formation with magnetically labeled endothelial progenitor cells. Biomaterials. 2007;28(26):3797-3806. doi:10.1016/j. biomaterials.2007.04.047

21. Vaněček V, Zablotskii V, Forostyak S, et al. Highly efficient magnetic targeting of mesenchymal stem cells in spinal cord injury. Int J Nanomedicine. 2012;7:3719-3730. doi:10.2147/IJN.S32824
22. Wilhelm C, Gazeau F, Bacri HC. Magnetophoresis and ferromagnetic resonance of magnetically labeled cells. Eur Biophys J. 2002;31 (2):118-125.

23. Kyrtatos PG, Lehtolainen P, Ramirez MJ, et al. Magnetic tagging increases delivery of circulating progenitors in vascular injury. JACC Cardiovasc Interv. 2009;2(8):794-802. doi:10.1016/j.jcin.2009.05.014

24. Cheng K, Malliaras K, Li TS, et al. Magnetic enhancement of cell retention, engraftment, and functional benefit after intracoronary delivery of cardiac-derived stem cells in a rat model of ischemia/ reperfusion. Cell Transplant. 2012;21(6):1121-1135. doi:10.3727/ 096368911 X627381

25. Li Q, Tang G, Xue S, et al. Silica-coated superparamagnetic iron oxide nanoparticles targeting of EPCs in ischemic brain injury. Biomaterials. 2013;34(21):4982-4992. doi:10.1016/j.biomaterials. 2013.03.030

26. Riegler J, Liew A, Hynes SO, et al. Superparamagnetic iron oxide nanoparticle targeting of MSCs in vascular injury. Biomaterials. 2013;34(8):1987-1994. doi:10.1016/j.biomaterials.2012.11.040

27. Oshima S, Kamei N, Nakasa T, Yasunaga Y, Ochi M. Enhancement of muscle repair using human mesenchymal stem cells with a magnetic targeting system in a subchronic muscle injury model. J Orthop Sci. 2014;19(3):478-488. doi:10.1007/s00776-014-0548-9

28. Meng Y, Shi C, Hu B, et al. External magnetic field promotes homing of magnetized stem cells following subcutaneous injection. BMC Cell Biol. 2017;18(1):1-12. doi:10.1186/s12860-016-0124-6

29. Arbab AS, Wilson LB, Ashari P, et al. A model of lysosomal metabolism of dextran coated superparamagnetic iron oxide (SPIO) nanoparticles: implications for cellular magnetic resonance imaging. NMR Biomed. 2005;18(6):383-389. doi:10.1002/nbm.970

30. Nishida K, Tanaka N, Nakanishi K, et al. Magnetic targeting of bone marrow stromal cells into spinal cord: through cerebrospinal £uid. Neuroreport. 2006 Aug 21;17(12):1269-72.

31. Ripa RS, Haack-Sørensen M, Wang Y, et al. Bone marrow derived mesenchymal cell mobilization by granulocyte-colony stimulating factor after acute myocardial infarction: results from the Stem Cells in Myocardial Infarction (STEMMI) trial. Circulation. 2007;116(11):124-130.

32. Kawada H, Fujita J, Kinjo K, et al. Nonhematopoietic mesenchymal stem cells can be mobilized and differentiate into cardiomyocytes after myocardial infarction. Blood. 2004;104(12):3581-3587.

33. Duijvestein M, Vos ACW, Roelofs H, et al. Autologous bone marrowderived mesenchymal stromal cell treatment for refractory luminal Crohn's disease: results of a phase I study. Gut. 2010;59(12):1662-1669.

34. Zappia E, Casazza S, Pedemonte E, et al. Mesenchymal stem cells ameliorate experimental autoimmune encephalomyelitis inducing T-cell energy. Blood. 2005;106(5):1755-1761.

35. Ehling A, Karrer S, Klebl F, et al. Therapeutic management of pyoderma gangrenosum. Arthritis Rheum. 2004;50(10):3076-3084.

36. Karp JM, Leng Teo GS. Mesenchymal stem cell homing: the devil is in the details. Cell Stem Cell. 2009;4(3):206-216.

37. Loebinger MR, Janes SM. Stem cells as vectors for antitumour therapy. Thorax. 2010;65(4):362-369.

38. Doucette T, Rao G, Yang Y, et al. Mesenchymal stem cells display tumor-specific tropism in an RCAS/Ntv-a glioma model. Neoplasia. 2011;13(8):716-725.

39. Spaeth E, Klopp A, Dembinski J, et al. Inflammation and tumor microenvironments: defining the migratory itinerary of mesenchymal stem cells. Gene Ther. 2008;15(10):730-738.

40. Freyman T, Polin G, Osman H, et al. A quantitative, randomized study evaluating three methods of mesenchymal stem cell delivery following myocardial infarction. Eur Heart J. 2006;27(9):1114-1122.

41. Lee RH, Pulin AA, Seo MJ, et al. Intravenous hMSCs improve myocardial infarction in mice because cells embolized in lung are activated to secrete the anti-inflammatory protein TSG-6. Cell Stem Cell. 2009;5(1):54.

42. Lim J, Lanni C, Evarts ER, et al. Magnetophoresis of nanoparticles. ACS Nano. 2010;5(1):217-226. 
43. Hsiao JK, Tai MF, Chu HH, et al. Magnetic nanoparticle labeling of mesenchymal stem cells without transfection agent: cellular behavior and capability of detection with clinical $1.5 \mathrm{~T}$ magnetic resonance at the single cell level. Magn Reason Med. 2007;58(4):717-724.

44. Yanai A, Häfeli UO, Metcalfe AL, et al. Focused magnetic stem cell targeting to the retina using superparamagnetic iron oxide nanoparticles. Cell Transplant. 2012;21(6):1137-1148.

45. Wang YX. Current status of superparamagnetic iron oxide contrast agents for liver magnetic resonance imaging. World J Gastroenterol. 2015;21(47):13400-13402.

46. Jo YK, Kim BH, Jung G. Antifungal activity of silver ions and nanoparticles on phytopathogenic fungi. Plant Dis. 2009;93(10):1037-1043.

47. Marędziak M, Tomaszewski K, Polinceusz P, et al. Static magnetic field enhances the viability and proliferation rate of adipose tissue-derived mesenchymal stem cells potentially through activation of the phosphoinositide 3-kinase/Akt (PI3K/Akt) pathway. Electromagn Biol Med. 2017;36(1):45-54.

48. Chen J, Huang N, Ma B, et al. Guidance of stem cells to a target destination in vivo by magnetic nanoparticles in a magnetic field. ACS Appl Mat Interfaces. 2013;5(13):5976-5985.

49. Diana V, Bossolasco P, Moscatelli D, et al. Dose dependent side effect of superparamagnetic iron oxide nanoparticle labeling on cell motility in two fetal stem cell populations. PLoS One. 2013;8(11): e78435.
50. Schäfer R, Kehlbach R, Wiskirchen J, et al. Transferrin receptor upregulation: in vitro labeling of rat mesenchymal stem cells with superparamagnetic iron oxide. Radiology. 2007;244(2):514-523.

51. Marycz K, Kornicka K, Röcken M. Static Magnetic Field (SMF) as a regulator of stem cell fate - new perspectives in regenerative medicine arising from an underestimated tool. Stem Cell Rev. 2018;14(6):785-792. doi:10.1007/s12015-018-9847-4

52. Lew WZ, Huang YC, Huang KY, et al. Static magnetic fields enhance dental pulp stem cell proliferation by activating the $\mathrm{p} 38$ mitogen-activated protein kinase pathway as its putative mechanism. J Tissue Eng Regen Med. 2018;12(1):19-29. doi:10.1002/term.2333

53. Connell JJ, Patrick PS, Yu Y, et al. Advanced cell therapies: targeting, tracking and actuation of cells with magnetic particles. Regen Med. 2015;10(6):757-772. doi:10.2217/rme.15.36

54. Arbab AS, Jordan EK, Wilson LB, et al. In vivo trafficking and targeted delivery of magnetically labeled stem cells. Human Gene Therapy. 2004;15(4):351-360.

\section{Publish your work in this journal}

The International Journal of Nanomedicine is an international, peerreviewed journal focusing on the application of nanotechnology in diagnostics, therapeutics, and drug delivery systems throughout the biomedical field. This journal is indexed on PubMed Central, MedLine, CAS, SciSearch ${ }^{\circledR}$, Current Contents ${ }^{\circledR} /$ Clinical Medicine,
Journal Citation Reports/Science Edition, EMBase, Scopus and the Elsevier Bibliographic databases. The manuscript management system is completely online and includes a very quick and fair peer-review system, which is all easy to use. Visit http://www.dovepress.com/ testimonials.php to read real quotes from published authors. 